\title{
Childhood Obesity Health Disorder Consequences and Preventive Initiatives to be Adopted for Better Healthy Lives
}

\section{Ramamohana Reddy Appannagari*}

Environmental Ecologist, CHEMTEX Environmental and Industrial Hygiene

Laboratory, Texas, USA

*Corresponding Author: Ramamohana Reddy Appannagari, Environmental

Ecologist, CHEMTEX Environmental and Industrial Hygiene Laboratory, Texas, USA.

DOI: 10.31080/ASNH.2020.04.0641
Received: January 18, 2020

Published: February 10, 2020

(C) All rights are reserved by Ramamohana

Reddy Appannagari.

\begin{abstract}
Obesity is a major threat to children's health today. The prevalence of obesity has been steadily increasing over the 35 years and the number of obese children has nearly tripled. Obesity means having too much body fat. It is different from being overweight, which means increase too much weight. The process of obesity development is not fully understood, and it is believed to be, a disorder with multiple causes. Family, socio-cultural environmental lifestyle preferences, and cultural environment play pivotal roles in the rising prevalence of obesity worldwide. On the other hand, there are supporting evidence that excessive sugar intake by soft drink, increased portion size, and steady decline in physical activity have been playing major roles in the rising rates of obesity all around the world. Childhood obesity can profoundly affect children's physical health, social, and emotional well-being, and self-esteem. It is associated with poor academic performance and a lower quality of life experienced by the child. Many co-morbid conditions like metabolic, cardiovascular, orthopedic, neurological, hepatic, pulmonary, and renal disorders are also seen in association with childhood obesity.
\end{abstract}

Keywords: Obesity; Health; Food; Fat

\section{Introduction}

Food is fuel for your body, just as gasoline is fuel for a car. Food gives you energy to do things. Most people use up the energy they get from food. Then they eat more food to get more energy. Some people eat more food than their bodies can use. When a person eats more food than his body needs, the extra food is stored as fat. A person who has a little bit too much extra fat on his body is overweight. When a person has a great deal of extra fat, then he is obese. A person who is obese may have problems doing everyday things such as walking upstairs, running, or even sleeping. Eating too much of the wrong kinds of foods also causes obesity. Such foods include candy, doughnuts, potato chips, and soda. These foods have a lot of sugar, fat, and carbohydrates. None of these things are good for your body in large amounts. Eating a lot of pasta, bread, and other foods that are high in carbohydrates can also cause a person to gain weight. Childhood obesity is a national epidemic. Nearly 1 in 3 children (ages 2-19) in the United States is overweight or obese, putting them at risk for serious health problems. As parents, caregivers, brothers and sisters, leaders in schools, communities and healthcare, we can work together to create a nation where the healthy choice is the easy choice. Obesity can be countered by creating more awareness about this problem, but this is possible only if people pay attention to the source of the problem. Solving childhood obesity takes work and coordination from multiple directions. Obesity can be a genetic problem or a disorder that is caused due to unhealthy lifestyle habits of a person. Physical inac- tivity and the environment in which an individual life, are also the factors that leads to obesity. It is also seen that when some individuals are in stress or depression, they start cultivating unhealthy eating habits which eventually leads to obesity. Medications for steroids is yet another reason for obesity.

\section{Causes of obesity}

Obesity currently is the biggest problem in the world and Childhood obesity is a complex health issue and having excess body fat. It's associated with several health conditions, collectively known as metabolic syndrome. Childhood obesity has become an epidemic and continues to be growing rapidly and more than one-third of children and adolescents are overweight or obese. Obesity prevalence has increased at an alarming rate, in 2016 the number overweight children under the age of five years. Overweight and obese children are likely to stay obese into adulthood and more likely to develop noncommunicable diseases. The people with metabolic syndrome are at a much higher risk of heart disease, health problems and type 2 diabetes compare to those whose weight is in a normal range. Usually occurs when a child is well above the normal or healthy weight for his or her age and height and main causes of excess weight gain in young people are like those in adults, including factors such as a person's behavior and genetics. Parents are the major role models for their children and their behavior can positively or negatively affect their children's health, a good dietary habit start at home. The most common factors responsible are so- 
ciety ignorance, unhealthy diet and insufficient personal exercise and excessive eating habits. Even children seem to be glued to televisions, laptops and video games which have taken away the urge for physical activities from them. Adding to this, the consumption of junk food has further aggravated the growing problem of obesity in children. In the case of adults, most of the professions of today make use of computers which again makes people sit for long hours in one place. Also, the hectic lifestyle of today makes it difficult for people to spare time for physical activities and people usually remain stressed most of the times. All this has contributed significantly to the rise of obesity at global level. Body Mass Index (BMI) is the measure which allows a person to calculate how to fit he or she is. In other words, the BMI tells you if you are obese or not. BMI is calculated by dividing the weight of a person in $\mathrm{kg}$ with the square of his/her height in meters. The number thus obtained is called the BMI. A BMI of less than 25 is considered optimal. However, if a person has a BMI over 30 , he/she is termed as obese.

\section{Family socio-cultural, psychological and environmental} causes

Family factors have also been associated with the increase of cases of obesity. The types of food available in the house and the food preferences of family members can influence the foods that children eat. While extensive television viewing and the use of other electronic media has contributed to the sedentary lifestyles, other environmental factors have reduced the opportunities for physical activity. Opportunities to be physically active and safe environments to be active in have decreased in the recent years. Most children in the past walked or rode their bike to school. Sociocultural factors have also been found to influence the development of obesity. Although some studies demonstrate no significant relationship between increased BMI and increased anxiety symptoms. Thus, the relationship between obesity and anxiety mat is not unidirectional and is certainly not conclusive.

\section{Prevention strategies and initiatives}

Eating the right amount of healthy food is important. When you eat smaller amounts, or portions, of healthy food, you will feel better. The trick to eating smaller portions is to listen to your body and stop eating when you are no longer hungry. If you eat more slowly, it will give your body time to know it is full. It can help to stop eating halfway through a meal and ask yourself if you are still hungry. If the answer is no, stop eating. It is also important to choose healthy foods, such as fruits and vegetables. If you are obese, your parents might take you to a doctor or a nutritionist. The simplest and most effective way, to begin with, is changing our diet. There are two factors to consider in the diet plan. First is what and what not to eat. Second is how much to eat. If you really want to get rid of obesity, include more and more green vegetables in your diet. Healthy greens such as spinach, lettuce, asparagus, broccoli, are vital for sustaining a balanced diet. Oranges, grapes, pomegranate, pineapple, cherries, strawberries, lime, provide important nutrients for building a strong immune system. Salads and fruits are great ways to start eating healthy and gaining essential nutrients. Vegetables provide important nutrients for supporting the many functions of the body. A good diet of meats such as chicken, fish, eggs, and more provide protein for building a strong body. Water is very important for transporting nutrients around the body; therefore, it should be prioritized heavily.

Control of diet and the quantity of the diet should be enforced in everyday lifestyle. Maintaining the determination to pursue a healthy lifestyle should be a number one priority to people's everyday activities. If integrated into daily lifestyle, people can enjoy physical activity through engaging in hobbies such as meditation, playing sports, jogging, and more. Severe cases should be consulted with a specialized physician on some cases. However, the implementation of strategies and encouragement of better lifestyles can be more impactful to people and the generations after them. Some strategies can be integrated into people's lifestyle with flexibility. The strategies are flexible without regard to location or institution and can be initiated anywhere. The strategies should encompass tasks around culture and environmental motivations, as this can help build commitment and determination. These strategies can help build awareness of unhealthy intakes of common unhealthy food, including a strong physical regiment of at least 60 minutes of activity a day. Good physical activity and a healthy diet can be a difficult change, but it is ultimately the only way to pursue a better and healthy lifestyle. External influences such as marketing by corporations, and expenses of healthy food options create an irregular pattern of unhealthy diet. Additionally, the importance of diet diminishes which correlates to lower physical activity and produces a general idea that nutrition and exercise are not as imperative as lauded to be [1-20].

\section{Conclusion}

It is no fun to be obese, and it is bad for your health, too. If you are obese, you may need to ask for help. Solving childhood obesity takes work and coordination from multiple directions. Adopt changes in schools, educating parents, and empowering young people are just some of the important parts of creating a healthier generation and explore the options to find out how you can get more involved in this worthwhile process With fewer unhealthy foods around, you will make better choices about what to eat. Your parents can also help find fun ways for you to stay active. They might also take you to a doctor, therapist, or nutritionist for more ideas about how you can live a healthier life. When you start exercising and eating healthier foods, you will feel better. You will have more energy. You will be able to do more. You will feel better about yourself, too. Physical activity and a balanced diet can combat Obesity and can help build habits to prevent an unhealthy lifestyle. Obesity is not taken as seriously, which is a dangerous sign of future populations health lifestyle. Obesity can be easily countered through proper diet and balanced physical activity. Obesity is even more dangerous than is initially perceived, and without proper attention obesity can impact an individual's life and health in a myriad of ways. the presence of an influence, Children are more likely to engage in unhealthy habits that can potentially compromise many facets of their lives in the future. According to the CDC, the environment plays a large role in an individual's involvement in physi- 
cal activity and the pursuit of a nutritional diet. There are many ways you can do to lose weight and improve your health and one of the best things do something active every day. Although parents can play a major role in preventing childhood obesity by becoming more involved in the child's healthy lives.

\section{Bibliography}

1. Cairns G., et al. "The extent, nature and effects of food promotion to children: a review of the evidence to December 2008". Geneva, World Health Organization (2009).

2. Council of Communications and Media. "Policy statementchildren, adolescents, obesity, and the media". Pediatrics (2011).

3. Stockley L., et al. "Nutrient profiles for use in relation to food promotion and children's diet: Update of 2004 literature review". Food Standard Agency, London (2008).

4. Suhrcke M., et al. "Economic consequences of chronic diseases and the economic rationale for public and private intervention". London, Oxford Health Alliance (2005).

5. Tohill B. "Dietary intake of fruit and vegetables and management of body weight". Geneva, World Health Organization (2005).

6. Singhal N., et al. "Effects of controlled school-based multicomponent model of nutrition and lifestyle interventions on behavior modification, anthropometry and metabolic risk profile of urban Asian Indian adolescents in North India". European Journal of Clinical Nutrition 64 (2010): 364-373.

7. Diet, nutrition and the prevention of chronic diseases. Geneva, World Health Organization and Food and Agricultural Organization (WHO Technical Report Series, No. 916) (2003).

8. Tohill B. "Dietary intake of fruit and vegetables and management of body weight". Geneva, World Health Organization (2005).

9. Global recommendations on physical activity for health. Geneva, World Health Organization (2010).

10. Parra D., et al. "Policy and built environment changes in Bogotá and their importance in health promotion". Indoor and Built Environment 16 (2007): 344-348.

11. King L., et al. "Best practice principles for community-based obesity prevention: development, content and application". Obesity Reviews (2011).

12. Schultz JT., et al. "Experiences and challenges in implementing complex community-based research project: The Pacific Obesity Prevention in Communities project". Obesity Reviews (2011).

13. Jiang J., et al. "The effects of a 3-year obesity intervention in schoolchildren in Beijing". Child: Care, Health and Development (2007).
14. Faith MS., et al. "Parent-child feeding strategies and their relationships to child eating and weight status". Obesity Research (2004).

15. Daniels SR., et al. "Overweight in children and adolescents: pathophysiology, consequences, prevention, and treatment". Circulation (2005).

16. Gregory JW and Lowe S. "National Diet and Nutrition Survey: Young People Aged 4 to 18 Years Report of the Diet and Nutrition Survey". London, The Stationery Office (2000).

17. "Political declaration of the high-level meeting of the General Assembly on the prevention and control of non-communicable diseases (A/66/L.1)". New York, United Nations, General Assembly (2011).

18. "Population-based prevention strategies for childhood obesity: report of a WHO forum and technical meeting, Geneva, 15-17 December 2009". Geneva, World Health Organization (2010): 19.

19. "Prioritizing areas for action in the field of population-based prevention of childhood obesity". Geneva, World Health Organization (2012).

20. "Global strategy on diet, physical activity and health: a framework to monitor and evaluate implementation". Geneva, World Health Organization (2006).

\section{Assets from publication with us}

- Prompt Acknowledgement after receiving the article

- Thorough Double blinded peer review

- Rapid Publication

- Issue of Publication Certificate

- High visibility of your Published work

Website: https://www.actascientific.com/

Submit Article: https://www.actascientific.com/submission.php Email us: editor@actascientific.com

Contact us: +919182824667 